\title{
SERPINB3 protects from oxidative damage by chemotherapeutics through inhibition of mitochondrial respiratory complex I
}

\author{
Francesco Ciscato ${ }^{1,2}$ Marco Sciacovelli1,3, Gianmarco Villano², Cristian Turato ${ }^{2}$, \\ Paolo Bernardi ${ }^{1}$, Andrea Rasola ${ }^{1}$, Patrizia Pontisso ${ }^{2}$ \\ ${ }^{1}$ CNR Institute of Neuroscience and Department of Biomedical Sciences, University of Padova, Padova, Italy; \\ 2 Department of Medicine, University of Padova, Padova, Italy \\ 3 present address: Medical Research Council Cancer Unit, Hutchison/MRC Research Centre, Hills Road, Cambridge, United \\ Kingdom \\ Correspondence to: Andrea Rasola, email: rasola@bio.unipd.it \\ Keywords: SERPINB3; chemotherapeutics; mitochondria; respiratory complexes; reactive oxygen species; cell death \\ Received: September 13,2013 Accepted: December 24, $2013 \quad$ Published: December 24, 2013
}

This is an open-access article distributed under the terms of the Creative Commons Attribution License, which permits unrestricted use, distribution, and reproduction in any medium, provided the original author and source are credited.

\section{ABSTRACT:}

SERPINB3 (SB3) is a serine protease inhibitor overexpressed in several malignancies of epithelial origin, including primary liver cancer, where it inhibits apoptosis through poorly defined mechanisms. In the present study we analyze the effect of SB3 on hepatoma cell death elicited by a panel of chemotherapeutic agents. We report that SB3 shields cells from the toxicity of drugs with a pro-oxidant action such as doxorubicin, cisplatin and EM20-25. The rapid rise in ROS levels prompted by these compounds causes opening of the mitochondrial permeability transition pore (PTP), irreversibly committing cells to death. We find that a fraction of SB3 locates in mitochondrial inner compartments, and that this mitochondrial fraction increases under conditions of oxidative stress. Mitochondrial SB3 inhibits ROS generation and the ensuing PTP induction and cell death through an inhibitory interaction with respiratory Complex $I$. These findings identify a novel mechanism of action of SB3 that contributes to tumor cell resistance to anti-neoplastic drugs

\section{INTRODUCTION}

Serpins (serine protease inhibitors) are inhibitors of both serine and cysteine proteases [1] characterized by a marked conformational flexibility, which allows to control proteolysis in biological processes as diverse as inflammation, blood coagulation and pressure regulation, chromatin condensation, protein folding, and tumor progression $[2,3]$. Serpins can also act independently of their protease inhibitory functions, e.g. as chaperones or hormone transporters [4].

SERPINB3 (SB3), previously known as Squamous Cell Carcinoma Antigen 1 (SCCA1), a member of the ovserpins/clade B serpin family [5], was originally purified from squamous cell carcinoma of the uterine cervix [6].

SB3 is physiologically detected in the superficial and intermediate layers of normal squamous epithelium and it is overexpressed in neoplasms of epithelial or endodermal origins such as lung cancer, head and neck cancer, melanoma, and hepatocellular carcinoma [6-10]. SB3 can neutralize proteinases of the cathepsin family [11], and in cancer cells it confers resistance to drug-induced apoptosis by inhibiting lysosomal cathepsin proteases [12]. However, under a variety of stress conditions SB3 displays an anti-apoptotic function unrelated to its proteinase inhibition activity $[6,13]$. Indeed, SB3 protects cells from exposure to radiation through an inhibitory effect either on the MAP family kinase JNK [13] or on p38 [14]; in epithelial ovarian cancer cells exposed to cisplatin, SB3 expression is associated with drug resistance and poor progression-free survival [15], whereas it inhibits the release of mitochondrial cytochrome $c$ in squamous cell carcinoma after treatment with TNF- $\alpha[16,17]$ or with DNA alkylating agents [18]. Moreover, SB3 expression is associated with poor survival in patients with breast cancer treated with anthracycline-based neoadjuvant chemotherapy [19] and in patients with epithelial ovarian cancer a high SB3 expression is a prognostic factor for platinum resistance and shorter progression-free survival [15]. Taken together, these observations suggest that SB3 
could favor tumor cell survival under stress conditions, even if the precise molecular mechanisms remain poorly understood.

Most stress and survival signals converge on mitochondria; these organelles are key players in cell death regulation [20] and contribute in several ways to the capability of escaping the lethal effects of stress stimuli that hallmark neoplasms [21]. A key component of the mitochondrial machinery that governs cell death is the permeability transition pore (PTP), an inner membrane channel whose stable opening constitutes a point of no return in cell commitment to death, as it induces mitochondrial depolarization and swelling with massive release of $\mathrm{Ca}^{2+}$, and rupture of the outer membrane with release of apoptogenic proteins. [22] A reduced sensitivity of mitochondrial PTP to diverse stress stimuli was described in in vitro and in vivo models of neoplastic transformation [23, 24], implying that inhibition of pore opening might be a strategy used by tumor cells to avoid death. PTP can be induced by oxidative stress $[23,25]$, and neoplasms are endowed with an enhanced generation of reactive oxygen species (ROS) compared with non-tumor cells. This altered homeostatic redox equilibrium is caused by several factors, one of the most important being dysregulation of mitochondrial respiratory chain complexes [26], which are the main sites of ROS production in the cell [27]. Thus, in order to set a novel homeostatic redox equilibrium, cancer cells must boost anti-oxidant defenses, and any further increase in ROS levels could overwhelm their residual anti-oxidant capabilities, resulting in the unlocking of PTP desensitization and in the selective killing of malignant cells.

Here we show an unprecedented mitochondrial localization of SB3, which binds respiratory Complex I, down-modulating its activity both in basal conditions and after cell treatment with pro-oxidant chemotherapeutics. By blocking ROS generation at Complex I, SB3 abrogates PTP opening and cell death induced by these drugs, shielding tumor cells from death.

\section{RESULTS}

\section{SB3 protects from cell death induced by antineoplastic agents}

In cancer cells, SB3 was reported to have an antiapoptotic activity under a variety of stress conditions [13, $14,16,17]$. Thus, SB3 could contribute to the ability of tumor cells to escape death. We chose human hepatoma HepG2 and HUH7 cells, which do not show detectable levels of endogenous SB3, as recipient cells to perform a stable SB3 transfection (Fig. 1A and Fig. S1A). To assess the survival role of SB3, we treated cells with a panel
A

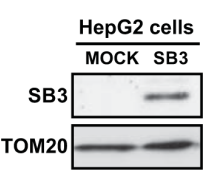

B

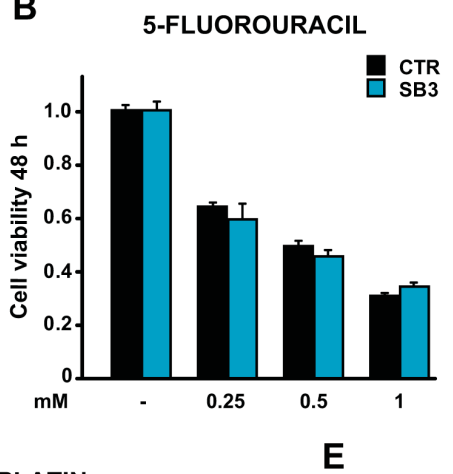

E
C

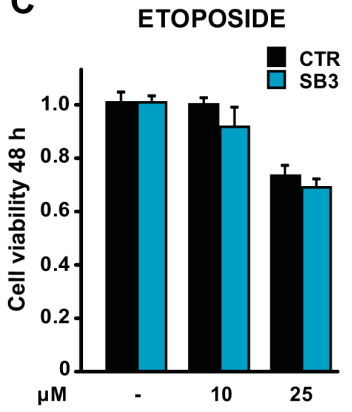

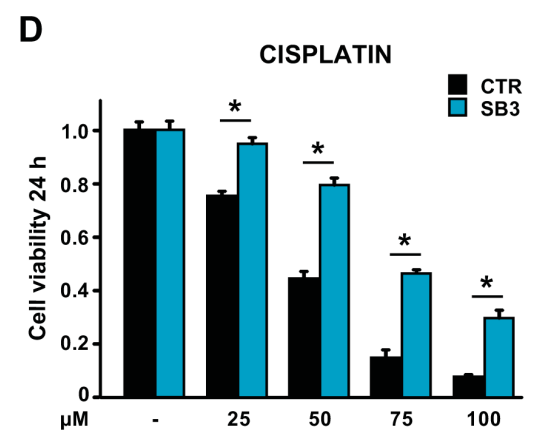

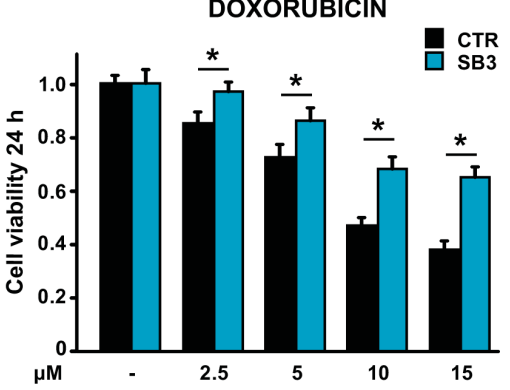

Figure 1: Effect of SB3 expression on the response of HepG2 cells to chemotherapeutics. (A) SB3 expression in human hepatoma HepG2 cells stably transfected with a mock construct or with a SB3 plasmid. TOM20 was used as a loading control of the Western immunoblot. (B-E) MTT analysis of cell viability after treatment with the reported concentrations of the chemotherapeutics 5-fluorouracil (B), etoposide (C), cisplatin (D) and doxorubicin (E). Cells were treated for 48 hours with 5-fluorouracil and etoposide, and for 24 hours with cisplatin and doxorubicin. Bars are mean values \pm S.D. of tetrazolium salt absorbance for $2 \times 10^{4}$ recorded cells $(n=6$, *, $\mathrm{p}<0.005$ with a Student's $t$ test). 
of chemotherapeutics: cisplatin, doxorubicin, 5-fluorouracil, etoposide and actinomycin D. We found that SB3 expression protected hepatoma cells from the toxicity of both cisplatin and doxorubicin in a dose-dependent fashion, while it was not effective on cells treated with 5-fluoro-uracil, etoposide or actinomycin D (Fig. 1B-E and Fig. S1B-C-F).

\section{SB3 prevents oxidative stress-induced cell death}

Both cisplatin and doxorubicin elicit a rapid surge of ROS, mainly from mitochondria, independently of their effect as DNA damaging agents [28-31]. We therefore hypothesized that SB3 could prevent cell death caused by oxidative stress. Indeed, SB3 expression strongly inhibited the increase in intracellular ROS levels prompted by cisplatin (Fig. 2A) and doxorubicin (Fig. S1D). Moreover, treatment of hepatoma cells with the antioxidant compound $\mathrm{N}$-acetyl-cysteine (NAC) mimicked the effect of SB3, in that it markedly inhibited both the ROS surge (Fig. 2A and Fig. S1D) and death induction caused by cisplatin and doxorubicin (Fig. 2B and Fig. S1B and $\mathrm{S} 1 \mathrm{E})$. Similar to SB3 expression, NAC could not protect hepatoma cells from toxicity elicited by 5-fluoro-uracil, etoposide or actinomycin D (Fig. S1C and S1F), which indicates that these drugs do not induce oxidative stress, and further support the hypothesis of an anti-oxidant role of SB3.

\section{Mitochondrial localization of SB3}

One of the main sites of ROS production in the cell is the mitochondrial respiratory chain, and mitochondria contribute to the neoplastic process by regulating redox equilibrium changes [27], energy metabolism [32] and cell death [20]. We therefore evaluated the possibility that SB3 could regulate ROS levels by directly interacting with some mitochondrial components. In keeping with this hypothesis, we found that a significant proportion of SB3 was protected from digestion by trypsin concentrations able to degrade proteins of the outer mitochondrial membrane (Fig. 2C and Fig.
A

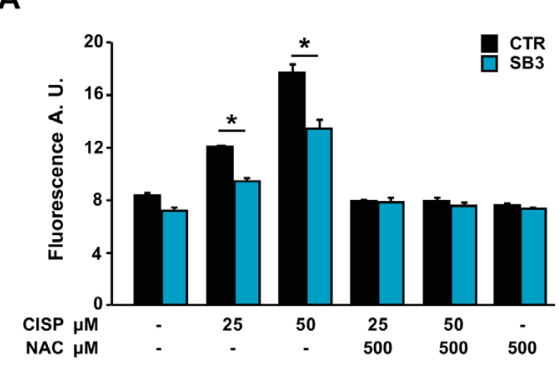

C

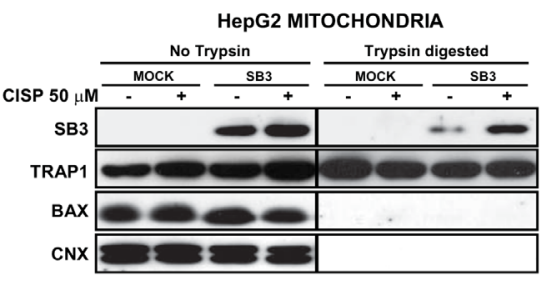

B

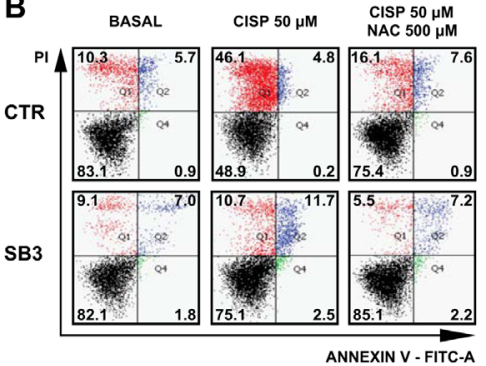

D

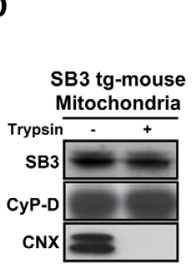

E

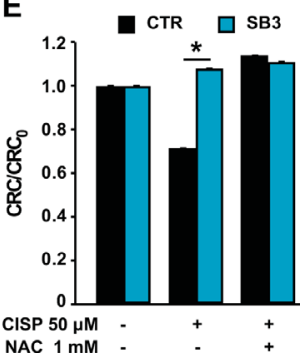

Figure 2: SB3 is located in mitochondria and inhibits oxidative stress and PTP opening. (A) Fluorimetric analysis of ROS levels in HepG2 cells treated for 5 hours with the reported cisplatin concentrations with or without N-acetyl-cysteine (NAC). Bars are mean values \pm S.D. of CM-H2DCFDA fluorescence (arbitrary units) for $2 \times 10^{4}$ recorded cells $\left(\mathrm{n}=6,{ }^{*}, \mathrm{p}<0.005\right.$ with a Student's $t$ test). (B) Representative traces of cytofluorimetric cell death analysis by Annexin-V and propidium iodide (PI) staining. In black, double negative, viable cells; in green, Annexin-V positive, apoptotic cells; in blue, Annexin-V/PI double positive, late apoptotic cells; in red, PI positive, necrotic cells. Numbers indicate the percentages of cells in each condition. Cells were treated for 24 hours with $50 \mu \mathrm{M}$ cisplatin; where indicated, NAC was added 1 hour before starting chemotherapeutic treatment. (C) Subcellular fractionation, partial trypsin digestion and Western immunoblot of the mitochondrial fractions of HepG2 cells. TRAP1 was used as a marker of mitochondrial matrix; Bax as a marker of outer mitochondrial membrane; calnexin (CNX) was used as an endoplasmic reticulum marker to check for purity of mitochondrial fractions. $50 \mu \mathrm{g}$ of mitochondrial proteins were loaded per lane. (D) Partial trypsin digestion and Western immunoblot of wild-type and SB3-transgenic mouse liver mitochondria. Cyclophilin D (CyP-D) was used as a marker of mitochondrial matrix, CNX was used as an endoplasmic reticulum marker to check for purity of mitochondrial fractions. $50 \mu \mathrm{g}$ of mitochondrial proteins were loaded per lane. (E) PTP opening of HepG2 cells treated with cisplatin is measured with the whole-cell CRC assay. Where indicated, cells were pretreated with $\mathrm{N}$-acetyl-cysteine (NAC). Experiments were performed after 16 hours of drug treatment, i.e. before the beginning of the cell death process, and were carried out in a glutamate/malate buffer to maximize Complex I activity. Bars indicate the ratio between the CRC detected in the different experimental conditions (CRC) and in untreated cells $\left(\mathrm{CRC}_{0} ; \mathrm{n}=6,{ }^{*}, \mathrm{p}<0.005\right.$ with a Student's $t$ test). A CRC/CRC ${ }_{0}$ lower than 1 indicates PTP induction. 
S1G), indicating that SB3 mainly locates in the inner mitochondrial compartments; and that treatment with cisplatin increased the mitochondrial fraction of SB3 (Fig. 2C). As a mitochondrial localization of SB3 was never reported before, we checked for its subcellular distribution in transgenic mice expressing SB3 in the liver [33] and in other human cancer cell models, including H295R adrenocortical carcinoma cells and SAOS-2 osteosarcoma cells, confirming that SB3 localizes in the mitochondrial matrix (Fig. 2D and Fig. S1G-H).

\section{SB3 abrogates PTP opening induced by oxidative stress}

Taken together, these observations suggest that SB3 displays a protective function against oxidative insults by impinging upon mitochondrial redox equilibrium. Increased levels of mitochondrial ROS can lead to cell death through opening of the PTP [23]. To test if SB3 shields cells from oxidative stress by inhibiting ROSdependent pore opening we performed a whole-cell $\mathrm{Ca}^{2+}$ retention capacity (CRC) assay [34], which measures the $\mathrm{Ca}^{2+}$ threshold for PTP opening in permeabilized cells exposed to a train of repeated $\mathrm{Ca}^{2+}$ pulses, as accumulation of $\mathrm{Ca}^{2+}$ into mitochondria induces the PTP. Since Complex $\mathrm{I}$ is one of the main sites of superoxide production in the cell [35], this experiment was carried out under conditions that maximize the activity of respiratory chain Complex $\mathrm{I}$, i.e. in a buffer containing glutamate/malate. Our data indicate that in HepG2 cells cisplatin sensitizes the PTP to $\mathrm{Ca}^{2+}$ in a ROS-dependent way, as its effect is inhibited by NAC; and, remarkably, that SB3 expression abrogates PTP induction by cisplatin (Fig. 2E).

To gain further insights on the mechanisms by which SB3 protects from PTP opening, we looked for additional compounds that induce oxidative stress and the ensuing PTP opening. The BH3 mimetic EM20-25, a well-characterized PTP opener in several tumor cell types [36], elicited a massive and fast death in HepG2 mock cells, which was paralleled by a rapid increase in ROS levels (Fig. 3A and 3B). When cells were pre-treated with NAC, EM20-25 toxicity was totally abolished (Fig. 3A), indicating the major involvement of oxidative stress in the observed EM20-25 effect. Notably, SB3 expression shielded HepG2 cells from both EM20-25 lethality and from the ROS surge elicited by the drug (Fig. 3A and 3B). EM20-25 displayed a clear pro-oxidant effect also in

A
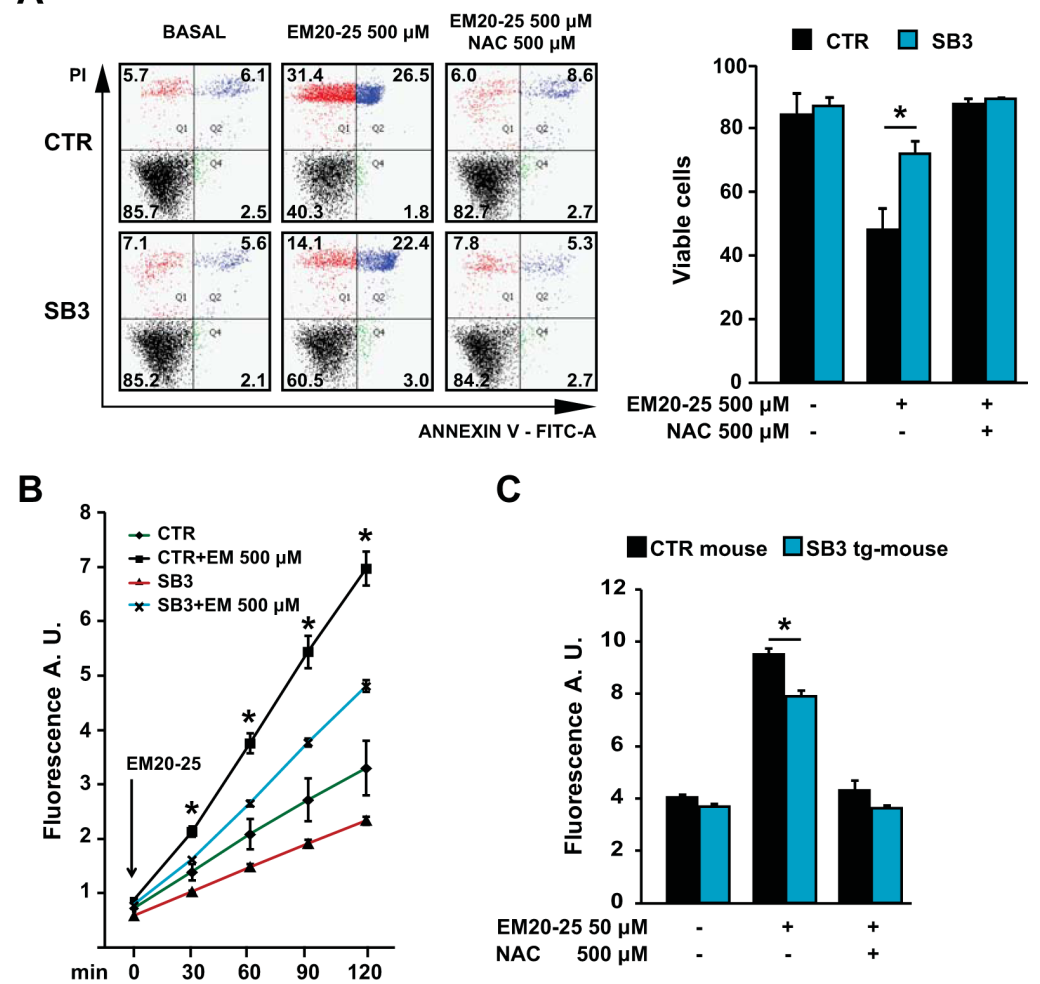

Figure 3: SB3 protects from oxidative stress and cell death elicited by the PTP opener EM20-25. (A) Representative traces of cytofluorimetric cell death analysis by Annexin- $\mathrm{V}$ and propidium iodide (PI) staining. In black, double negative, viable cells; in green, Annexin-V positive, apoptotic cells; in blue, Annexin-V/PI double positive, late apoptotic cells; in red, PI positive, necrotic cells. Numbers indicate the percentages of cells in each condition. Cells were treated for $2 \mathrm{~h} 30 \mathrm{~min}$ with EM $500 \mu \mathrm{M}$; where indicated, $500 \mu \mathrm{M}$ N-acetylcysteine (NAC) was added 1 hour before starting chemotherapeutic treatment. (B, C) Fluorimetric analysis of ROS levels in HepG2 cells (B) and in wild-type and SB3-transgenic mouse liver mitochondria (C) treated for 2 hours with the reported EM20-25 concentrations; where indicated, N-acetyl-cysteine (NAC) was added 1 hour before starting the experiment. Bars are mean values \pm S.D. of CM-H2DCFDA fluorescence (arbitrary units) for $2 \times 10^{4}$ recorded cells or $200 \mu \mathrm{g}$ mitochondria ( $\mathrm{n}=6,{ }^{*}, \mathrm{p}<0.005$ with a Student's $t$ test). 
mouse liver mitochondria, where significant protection by SB3 was confirmed as well (Fig. 3C).

\section{SB3 interaction with Complex I}

High levels of ROS can be generated in mitochondria by compounds that modulate the activity of respiratory complexes on the inner membrane. As we found SB3 in inner mitochondrial compartments, we investigated if it could directly interact with the respiratory chain. Co-immunoprecipitations experiments revealed an association between respiratory Complex I and SB3 both in HepG2-SB3 cells and in liver mitochondria of SB3 transgenic mice (Fig. 4A and 4B). Importantly, the physical association between SB3 and Complex I had a functional effect, as the presence of SB3 markedly inhibited the enzymatic activity of Complex I of both cultured cells and mouse liver mitochondria (Fig. 4C and 4D).

Dysregulation of ROS generated by Complex I could trigger an oxidative stress capable of opening the PTP [37]. Indeed, the PTP opener EM20-25 strongly increased Complex I activity, and SB3 totally blunted Complex I induction by EM20-25 (Fig. 4C). Thus, modulation of Complex I activity could have a key role on redox equilibrium, and on PTP opening elicited by oxidative insults. Accordingly, CRC experiments carried out in a glutamate/malate buffer demonstrated that EM20-25 induces the PTP in a ROS-dependent way, as this induction was abrogated by NAC-dependent ROS scavenging (Fig. 4E). Remarkably, SB3 expression had an inhibitory effect on PTP induction that closely resembled that of NAC (Fig. 4E). Taken together, these observations indicate that SB3 protects cells from the lethal effects of oxidative insults by inhibiting ROS generation by Complex I and the ensuing PTP opening.

\section{DISCUSSION}

In the present work we have characterized a novel activity of SB3 that may have important implications in the tumorigenic process. We have found that a fraction of SB3 is located in the inner mitochondrial compartments, where it binds respiratory Complex I and down-modulates its activity. By a parallel inhibition of ROS generation at Complex I, SB3 shields cells from the noxious effects of oxidative stress, in particular from death-inducing PTP opening caused by chemotherapeutic agents that also act as pro-oxidants. Since SB3 is over-expressed in several epithelial tumors $[6,7,9]$ and in preneoplastic liver lesions, [8] it can be considered an important component of the anti-apoptotic machinery installed by neoplastic cells to survive the variety of stress conditions they encounter during malignant progression. In addition, the recently described resistance to chemotherapeutics and the poor prognosis of patients with both breast [19] and ovarian cancer [15] over-expressing SB3 are in keeping with the results of this study.

Beside the antiprotease activity, a high degree of functional pleiotropy has been associated with SB3, including involvement in tissue remodeling during fibrosis associated to autoimmune diseases $[6,38]$, induction of TGF- $\beta[39,40]$ and of the oncogene Myc [41] and hepatocyte proliferation after partial hepatectomy [33]. Together with its anti-apoptotic activity, all these functions of SB3 could contribute to neoplastic progression. Indeed, inhibition of NK cell recruitment, and of NK cell-induced apoptosis [1], could attenuate the anti-
A

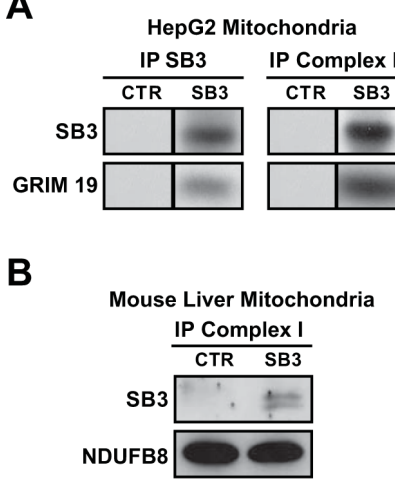

C

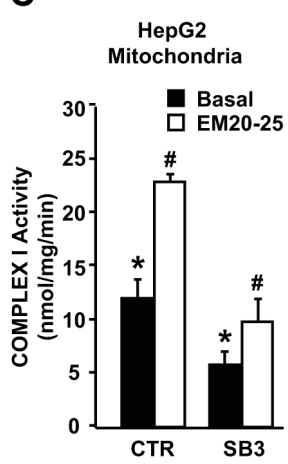

D

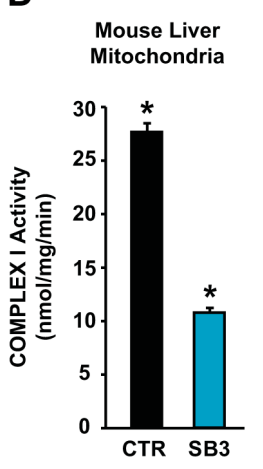

E

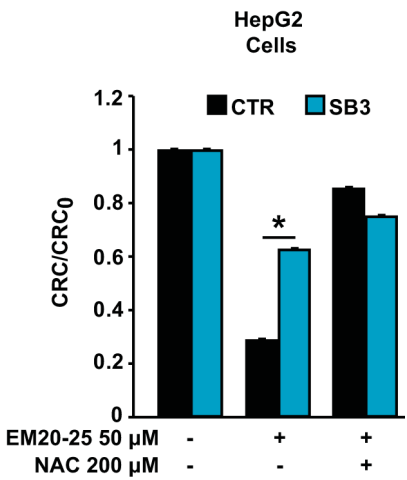

Figure 4: SB3 interacts with respiratory Complex I and inhibits its enzymatic activity. (A, B) SB3 and Complex I and TRAP1 immunoprecipitations (IPs) on mitochondria from HepG2 cells (A) and on wild-type and SB3-transgenic mouse liver mitochondria (B). The interaction between SB3 and Complex I is shown by co-IP; to detect Complex I, two different subunits (GRIM19 and NDUFB8) were probed. (C, D) Spectrophotometric analysis of the NADH:ubiquinone oxidoreductase enzymatic activity of complex I in mitochondria from HepG2 cells (C) or from mouse liver (D); both in (C) and in (D), n=6, *, p<0.005 with a Student's t test). (E) PTP opening of HepG2 cells treated with EM20-25 is measured with the whole-cell CRC assay. Where indicated, cells were pretreated with $\mathrm{N}$-acetyl-cysteine (NAC). Experiments were carried out in a glutamate/malate buffer to maximize Complex I activity. Bars indicate the ratio between the CRC detected in the different experimental conditions (CRC) and in untreated cells (CRC0; $\mathrm{n}=6,{ }^{*}, \mathrm{p}<0.005$ with a Student's t test). A CRC/ CRC0 lower than 1 indicates PTP induction. 
tumor innate immunity response, which is consistent with increased tumor infiltration by NK cells in in vivo cancer models after SB3 inhibition [17]. Furthermore, SB3 expression was shown to prompt tissue remodeling and cell proliferation associated with increased $\beta$-catenin accumulation, which could play a role in epithelial mesenchymal transition [42] and invasion [43] of tumor cells.

Notably, the SB3-mediated modulation of redox that we report here could be part of this complex picture, as ROS contribute in stimulating proliferation, invasion and metastasis, and in inhibiting apoptosis [44]. Indeed, ROS play complex and multiple roles in the tumorigenic process. Several oncogenes increase ROS levels by unbalancing the energy metabolism pathways of the tumor cell, which can cause electron leakage during oxidative phosphorylation and stimulate generation of superoxide; and a surge in mitochondrial ROS stimulates cellular proliferation and anchorage-independent growth [45]. Nonetheless, tumor cells must reach a novel redox equilibrium, to avoid an uncontrolled rise in ROS levels that would trigger a feed-forward loop involving a progressive rise in $\mathrm{Ca}^{2+}$ concentration, a further ROS increase and eventually PTP opening and death [23, 25]. Neoplasms must therefore utilize several strategies to maintain a locked PTP, e.g. by the association of hexokinase II with mitochondria [34], or by signalling conveyed by kinases [24], such as a mitochondrial branch of an ERK/GSK-3 $\beta$ signalling axis [36]. In this framework, tumor cells could exploit SB3 as a further mechanism of defense from oxidative insults.

The diverse functions of SB3 are paralleled by its multiple locations, as the protein can be found both in nuclei and cytoplasm, and it can also be released from tumor cells [3], acting through both autocrine and paracrine pathways [42] and serving as tumoral or prognostic marker [46]. Here we have identified a novel site of SB3 expression in the mitochondrial matrix, where it is involved in an unprecedented function, i.e. protection from oxidative stress through interaction with the respiratory Complex I. Notably, SB3 further translocates into mitochondria following cisplatin treatment, which suggests its recruitment as a component of the mitochondrial anti-oxidant machinery. Most of the ROS generated in intact mitochondria are contributed by the NADH:quinone oxidoreductase activity of this enzyme [35]. The importance of Complex I-dependent oxidants is further highlighted by our recent observation that the Gold(III)-dithiocarbamato compound AUL12 induces neoplastic cell death by enhancing ROS generation at Complex I, thus triggering multiple signalling pathways that eventually lead to PTP opening [37]. The importance of regulation of respiratory chain complexes in cancer cells is becoming increasingly clear, as exemplified by the recent observations that activity of Complex I is inhibited in models of K-Ras-driven tumorigenesis [47], and that down-regulation of Complex II by the mitochondrial chaperone TRAP1 creates a pseudohypoxic phenotype that promotes tumorigenesis [48].

Redox alterations are postulated to make neoplastic cells particularly vulnerable to oxidants, and indeed ROS generation contributes to the toxicity of a variety of chemotherapeutics. Therefore, increased understanding of the molecular mechanisms by which SB3 protects tumor cells from oxidants has possible implications for developing anti-neoplastic strategies that target the altered redox equilibrium of SB3-expressing neoplasms.

\section{METHODS}

\section{Ethics statement}

Experiments with mice were authorized by the Animal Care and Use Committee of the University of Padova and carried out according to European guidelines.

\section{Cell culture transfections and SB3-transgenic mice}

HepG2 cells were cultured in Minimum Essential Medium (MEM; Sigma, St. Louis, Missouri) added with 10\% Fetal Bovine Serum (FBS; Invitrogen Life Technologies, Carlsbad - California), glutamine $2 \mathrm{mM}$ (Sigma), MEM non essential amino acids (Sigma), penicillin (100 units $/ \mathrm{ml})$, streptomycin $(100 \mu \mathrm{g} / \mathrm{ml}$; Invitrogen), and were kept in a humidified atmosphere of $5 \% \mathrm{CO} 2$ at $37^{\circ} \mathrm{C}$. Cells were stably transfected with a vector carrying the full length human SB3 cDNA inserted in a pCDNA3.1 vector, mock cells were obtained by stable transfection with an empty pCDNA3.1 plasmid, as described [42]. The study was carried out in C57BL/6 mice transgenic for human SB3 [33]. Mice were bred at the Animal Care Facility of the Experimental Surgery Division of the University of Padua.

\section{Cell viability assays}

To analyze viability after chemotherapeutic treatments, HepG2 cells were plated in 96-well plate ( $2 \times 10^{4}$ cells/well) and synchronized by a 24 hour FBS depletion. FBS was then re-added in the medium at the time of chemotherapeutic addition. Cell viability was assessed either with a MTS assay or by flow cytometry analysis. The MTS assay (CellTiter 96® AQueous One Solution; Promega, Madison, Wisconsin) exploits an improved tetrazolium compound, MTS (3-(4,5-dimethylthiazol-2yl)-5-(3-carboxymethoxyphenyl)-2-(4-sulfophenyl)-2Htetrazolium, inner salt), that is reduced by dehydrogenase enzymes of living cells into a formazan product whose 
absorbance at $490 \mathrm{~nm}$ is directly proportional to the number of viable cells. To perform colorimetric measurements, cells were washed with PBS and then a HBSS solution containing MTS was added. Plates were incubated at $37^{\circ} \mathrm{C}$ for $1 \mathrm{~h}$ and read in a Multiskan EX multiplate reader (Thermo Scientific, Waltham, Massachusetts). Flow cytometry recordings were performed as described previously [49, 50] to detect phosphatidylserine exposure on the cell surface (increased FITC-conjugated Annexin-V staining) and loss of plasma membrane integrity (propidium iodide staining, $1 \mu \mathrm{g} / \mathrm{ml}$ ). Samples were analyzed on a FACSCanto II flow cytometer (Becton Dickinson, Franklin Lakes, New Jersey). Data acquisition and analysis were performed using FACSDiva software (Becton Dickinson).

\section{Preparation of mitochondrial extracts}

To prepare mitochondrial extracts, either cells or minced mouse livers were placed in an isolation buffer (250 mM sucrose, $10 \mathrm{mM}$ Tris/HCl, $10 \mathrm{mM}$ EGTA/ Tris, $\mathrm{pH} 7.4$ with phosphatase and protease inhibitors) and homogenized at $4{ }^{\circ} \mathrm{C}$ with an electrical glass-Teflon potter. Mitochondria were then isolated by differential centrifugation (three times, the first at $700 \mathrm{x} g$ to eliminate nuclei, plasma membrane fractions and undisrupted cells and twice at $7,000 \times \mathrm{g}$, all at $4^{\circ} \mathrm{C}, 10$ minutes each to pellet and wash mitochondria) in mitochondrial isolation buffer. Protease digestion of isolated mitochondria was performed in isolation buffer without protease inhibitors for $1 \mathrm{~h}$ at $4^{\circ} \mathrm{C}$. After inactivating trypsin with a protease inhibitor cocktail (Sigma), mitochondria were spun $(18,000 \times \mathrm{g}$ for 10 minutes) and lysed.

\section{Western blot analyses and immunoprecipitations}

Total cell extracts were prepared at $4^{\circ} \mathrm{C}$ in 140 $\mathrm{mM} \mathrm{NaCl}, 20 \mathrm{mM}$ Tris/HCl (pH 7.4), 5mM EDTA, $10 \%$ glycerol, and $1 \%$ Triton X-100 in the presence of phosphatase and protease inhibitors (Sigma). All lysates were kept for 30 minutes on ice and then cleared by centrifugation at $4^{\circ} \mathrm{C}$ and $14,000 \times \mathrm{g}$ for 25 minutes. Protein quantification was performed with BCA Protein Assay Kit (Thermo Scientific-Pierce).

Immunoprecipitations were performed on $1 \mathrm{mg}$ of proteins extracted from total cell lysates and on 300 $\mu \mathrm{g}$ from isolated mitochondria cleared with protein A-Sepharose (Sigma) for $1 \mathrm{~h}$ at $4^{\circ} \mathrm{C}$. Incubation with the primary antibody $(1 \mu \mathrm{g}$ per sample) was carried out in agitation at $4^{\circ} \mathrm{C}$ for 16 hours. Western immunoblots were carried out under standard conditions, and proteins were transferred onto nitrocellulose Hybond-C Extra membranes (Amersham, Uppsala - Sweden) and visualized by enhanced chemiluminescence (Millipore, Milan, Italy).
Anti-SERPINB3 rabbit polyclonal antibody was from Xeptagen (Venezia, Italy); mouse monoclonal antiSERPINB3 (sc-21767), anti Grim19 (sc-271013) and anti TRAP1 (sc-13557) antibodies, rabbit polyclonal anti TOM20 (sc-11415), anti Bax (sc-493) and anti Calnexin (sc-6465) antibodies were all from Santa Cruz (Santa Cruz, California); mouse monoclonal anti CyP-D antibody (AP1035) was from Calbiochem (Darmstadt, Germany); mouse monoclonal anti GAPDH (MAB374) was from Merck Millipore (Billerica, Massachusetts); mouse monoclonal anti NDUFB8 (20E9DH10C12) and mouse monoclonal anti Complex I Immunocapture kit (ab109711) antibodies were from MitoSciences (Eugene, Oregon).

\section{ROS measurements}

To perform ROS measurements, cells were plated as for cell viability assays; isolated mitochondria (200 $\mu \mathrm{g} / \mathrm{well})$ were resuspended in a buffer containing 250 $\mathrm{mM}$ Sucrose, $10 \mathrm{mM}$ MOPS-Tris, $5 \mathrm{mM}$ Glutamate, $2.5 \mathrm{mM}$ Malate, $4 \mathrm{mM} \mathrm{MgCl}, 1 \mathrm{mM}$ Pi-Tris, at $\mathrm{pH}$ 7.4. ROS levels were detected by using the probe 5-(and-6)chloromethyl-2',7'-dichlorodihydrofluorescein diacetate, acetyl ester (CM-H2DCFDA, $1 \mu \mathrm{M}$; Molecular Probes, Carlsbad, - California). Fluorescence ( $\lambda$ exc: $485 \mathrm{~nm} ; \lambda$ em: $538 \mathrm{~nm}$ ) was recorded using a Fluoroskan Ascent FL (Thermo Electron Corp.) plate reader.

\section{Respiratory Complex I activity assay and Citrate Synthase activity assay}

The enzymatic activity of respiratory chain Complex I was assessed on freshly isolated mitochondria or permeabilized cells ( $40 \mu \mathrm{g}$ of proteins per trace). Samples were pre-incubated for $3 \mathrm{~min}$ at $37^{\circ} \mathrm{C}$ in a buffer composed by potassium phosphate $25 \mathrm{mM} \mathrm{pH}$ 7.4, alamethicin $1 \mu \mathrm{M}$, BSA $3 \mathrm{mg} / \mathrm{ml}$, sodium azide $(500 \mu \mathrm{M}), 6.5 \mu \mathrm{M}$ Coenzyme Q1. Reaction started after the addition of NADH $10 \mu \mathrm{M}$ and NADH consumption was recorded spectrophotometrically as a decrease in absorbance at a $340 \mathrm{~nm}$ wavelength for 5 minutes. The Complex I activity was calculated as NADH consumption assessing the difference of the trace slopes with or without the Complex I inhibitor Rotenone $10 \mu \mathrm{M}$. Each measurement of Complex I activity was normalized for Citrate Synthase (CS) activity. Citrate formation was spectrophotometrically measured as an increase in absorbance at $420 \mathrm{~nm}$ wavelength in a buffer containing $100 \mathrm{mM}$ Tris-HCl pH 8, $100 \mu \mathrm{M}$ DTNB, $300 \mu \mathrm{M}$ Acetyl -CoA, $500 \mu \mathrm{M}$ Oxaloacetate, at $37^{\circ} \mathrm{C}$. 


\section{Measurement of Mitochondrial $\mathrm{Ca}^{2+}$ Retention Capacity}

The CRC assay was performed as described to assess PTP opening in whole cells exposed to trains of $\mathrm{Ca}^{2+}$ pulses $[34,36]$. Briefly, cells were permeabilized with $100 \mu \mathrm{M}$ digitonin $\left(15 \mathrm{~min}, 4^{\circ} \mathrm{C}\right)$ in a high $(1 \mathrm{mM})$ EGTA buffer. Digitonin was then eliminated and permeabilized cells were placed in low $(10 \mu \mathrm{M})$ EGTA in the presence of $5 \mathrm{mM}$ Glutamate $/ 2.5 \mathrm{mM}$ Malate, $10 \mu \mathrm{M}$ cytochrome $c$, and of the $\mathrm{Ca}^{2+}$ probe Calcium Green- $5 \mathrm{~N}(1 \mu \mathrm{M} ; \lambda$ exc: $505 \mathrm{~nm} ; \lambda$ em: $535 \mathrm{~nm}$; Molecular Probes), which does not permeate mitochondria. Cells were then exposed to $\mathrm{Ca}^{2+}$ spikes, and fluorescence drops were used to assess mitochondrial $\mathrm{Ca}^{2+}$ uptake using a Fluoroskan Ascent FL (Thermo Electron Corp.) plate reader. PTP opening was detected as a sudden and irreversible fluorescence increase. The $\mathrm{Ca}^{2+}$ taken up by mitochondria before PTP opening in the different experimental conditions was then normalized to control conditions (dubbed as $\mathrm{CRC}_{0}$ ).

\section{ACKNOWLEDGEMENTS}

This study was supported by grants from PRIN/ MIUR and FIRB/MIUR (grant numbers RBAP11S8C 3 and RBLA03S4SP), from Progetti di Ateneo (grant numbers CPDA110795 and CPDA123598) and Progetti Strategici dell'Università di Padova and from the Associazione Italiana per la Ricerca sul Cancro (grant numbers 8722 and 13392). We thank Mariagrazia Ruvoletto and Santina Quarta for invaluable technical assistance.

\section{REFERENCES}

1. Gettins PG. Serpin structure, mechanism, and function. Chem Rev. 2002; 102(12):4751-4804.

2. Gooptu B and Lomas DA. Conformational pathology of the serpins: themes, variations, and therapeutic strategies. Annu Rev Biochem. 2009; 78:147-176.

3. Silverman GA, Bird PI, Carrell RW, Church FC, Coughlin PB, Gettins PG, Irving JA, Lomas DA, Luke CJ, Moyer RW, Pemberton PA, Remold-O'Donnell E, Salvesen GS, et al. The serpins are an expanding superfamily of structurally similar but functionally diverse proteins. Evolution, mechanism of inhibition, novel functions, and a revised nomenclature. J Biol Chem. 2001; 276(36):33293-33296.

4. Silverman GA, Whisstock JC, Bottomley SP, Huntington JA, Kaiserman D, Luke CJ, Pak SC, Reichhart JM and Bird PI. Serpins flex their muscle: I. Putting the clamps on proteolysis in diverse biological systems. J Biol Chem. 2010; 285(32):24299-24305.

5. Remold-O'Donnell E. The ovalbumin family of serpin proteins. FEBS Lett. 1993; 315(2):105-108.

6. Vidalino L, Doria A, Quarta S, Zen M, Gatta A and Pontisso
P. SERPINB3, apoptosis and autoimmunity. Autoimmun Rev. 2009; 9(2):108-112.

7. Cataltepe S, Gornstein ER, Schick C, Kamachi Y, Chatson K, Fries J, Silverman GA and Upton MP. Co-expression of the squamous cell carcinoma antigens 1 and 2 in normal adult human tissues and squamous cell carcinomas. J Histochem Cytochem. 2000; 48(1):113-122.

8. Guido M, Roskams T, Pontisso P, Fassan M, Thung SN, Giacomelli L, Sergio A, Farinati F, Cillo U and Rugge M. Squamous cell carcinoma antigen in human liver carcinogenesis. J Clin Pathol. 2008; 61(4):445-447.

9. Pontisso P, Calabrese F, Benvegnu L, Lise M, Belluco C, Ruvoletto MG, Marino M, Valente M, Nitti D, Gatta A and Fassina G. Overexpression of squamous cell carcinoma antigen variants in hepatocellular carcinoma. Br J Cancer. 2004; 90(4):833-837.

10. Turato C, Buendia MA, Fabre M, Redon MJ, Branchereau S, Quarta S, Ruvoletto M, Perilongo G, Grotzer MA, Gatta A and Pontisso P. Over-expression of SERPINB3 in hepatoblastoma: a possible insight into the genesis of this tumour? Eur J Cancer. 2011; 48(8):1219-1226.

11. Schick C, Pemberton PA, Shi GP, Kamachi Y, Cataltepe S, Bartuski AJ, Gornstein ER, Bromme D, Chapman HA and Silverman GA. Cross-class inhibition of the cysteine proteinases cathepsins $\mathrm{K}$, L, and $\mathrm{S}$ by the serpin squamous cell carcinoma antigen 1: a kinetic analysis. Biochemistry. 1998; 37(15):5258-5266.

12. Suminami Y, Nagashima S, Vujanovic NL, Hirabayashi $\mathrm{K}$, Kato $\mathrm{H}$ and Whiteside TL. Inhibition of apoptosis in human tumour cells by the tumour-associated serpin, SCC antigen-1. Br J Cancer. 2000; 82(4):981-989.

13. Katagiri C, Nakanishi J, Kadoya K and Hibino T. Serpin squamous cell carcinoma antigen inhibits UV-induced apoptosis via suppression of c-JUN NH2-terminal kinase. J Cell Biol. 2006; 172(7):983-990.

14. Murakami A, Suminami Y, Hirakawa H, Nawata S, Numa $\mathrm{F}$ and Kato H. Squamous cell carcinoma antigen suppresses radiation-induced cell death. Br J Cancer. 2001; 84(6):851858.

15. Lim W, Kim HS, Jeong W, Ahn SE, Kim J, Kim YB, Kim MA, Kim MK, Chung HH, Song YS, Bazer FW, Han JY and Song G. SERPINB3 in the chicken model of ovarian cancer: a prognostic factor for platinum resistance and survival in patients with epithelial ovarian cancer. PLoS One. 2012; 7(11):e49869.

16. Hashimoto K, Kiyoshima T, Matsuo K, Ozeki S and Sakai H. Effect of SCCA1 and SCCA2 on the suppression of TNF-alpha-induced cell death by impeding the release of mitochondrial cytochrome $\mathrm{c}$ in an oral squamous cell carcinoma cell line. Tumour Biol. 2005; 26(4):165-172.

17. Suminami Y, Nagashima S, Murakami A, Nawata S, Gondo T, Hirakawa H, Numa F, Silverman GA and Kato H. Suppression of a squamous cell carcinoma (SCC)-related serpin, SCC antigen, inhibits tumor growth with increased 
intratumor infiltration of natural killer cells. Cancer Res. 2001; 61(5):1776-1780.

18. Ullman E, Pan JA and Zong WX. Squamous cell carcinoma antigen 1 promotes caspase-8-mediated apoptosis in response to endoplasmic reticulum stress while inhibiting necrosis induced by lysosomal injury. Mol Cell Biol. 2011; 31(14):2902-2919.

19. Collie-Duguid ES, Sweeney K, Stewart KN, Miller ID, Smyth E and Heys SD. SerpinB3, a new prognostic tool in breast cancer patients treated with neoadjuvant chemotherapy. Breast Cancer Res Treat. 2011; 132(3):807818.

20. Tait SW and Green DR. Mitochondria and cell death: outer membrane permeabilization and beyond. Nat Rev Mol Cell Biol. 2010; 11(9):621-632.

21. Hanahan D and Weinberg RA. Hallmarks of cancer: the next generation. Cell. 2011; 144(5):646-674.

22. Rasola A and Bernardi P. The mitochondrial permeability transition pore and its involvement in cell death and in disease pathogenesis. Apoptosis. 2007; 12(5):815-833.

23. Rasola A and Bernardi P. Mitochondrial permeability transition in $\mathrm{Ca}(2+)$-dependent apoptosis and necrosis. Cell Calcium. 2011; 50:222-233.

24. Rasola A, Sciacovelli M, Pantic B and Bernardi P. Signal transduction to the permeability transition pore. FEBS Lett. 2010; 584(10):1989-1996.

25. Zorov DB, Juhaszova M and Sollott SJ. Mitochondrial ROS-induced ROS release: an update and review. Biochim Biophys Acta. 2006; 1757(5-6):509-517.

26. Cairns RA, Harris IS and Mak TW. Regulation of cancer cell metabolism. Nat Rev Cancer. 2011; 11(2):85-95.

27. Murphy MP. How mitochondria produce reactive oxygen species. Biochem J. 2009; 417(1):1-13.

28. Itoh T, Terazawa R, Kojima K, Nakane K, Deguchi T, Ando $\mathrm{M}$, Tsukamasa $\mathrm{Y}$, Ito $\mathrm{M}$ and Nozawa $\mathrm{Y}$. Cisplatin induces production of reactive oxygen species via NADPH oxidase activation in human prostate cancer cells. Free Radic Res. 2011; 45(9):1033-1039.

29. Kuznetsov AV, Margreiter R, Amberger A, Saks V and Grimm M. Changes in mitochondrial redox state, membrane potential and calcium precede mitochondrial dysfunction in doxorubicin-induced cell death. Biochim Biophys Acta. 2011; 1813(6):1144-1152.

30. Lu Y and Cederbaum A. The mode of cisplatin-induced cell death in CYP2E1-overexpressing HepG2 cells: modulation by ERK, ROS, glutathione, and thioredoxin. Free Radic Biol Med. 2007; 43(7):1061-1075.

31. Santandreu FM, Roca P and Oliver J. Uncoupling protein-2 knockdown mediates the cytotoxic effects of cisplatin. Free Radic Biol Med. 2010; 49(4):658-666.

32. Frezza $\mathrm{C}$ and Gottlieb E. Mitochondria in cancer: not just innocent bystanders. Semin Cancer Biol. 2009; 19(1):4-11.

33. Villano G, Quarta S, Ruvoletto MG, Turato C, Vidalino L, Biasiolo A, Tono N, Lunardi F, Calabrese F, Dall'olmo L,
Dedja A, Fassina G, Gatta A, et al. Role of squamous cell carcinoma antigen-1 on liver cells after partial hepatectomy in transgenic mice. Int J Mol Med. 2010; 25(1):137-143.

34. Chiara F, Castellaro D, Marin O, Petronilli V, Brusilow WS, Juhaszova M, Sollott SJ, Forte M, Bernardi P and Rasola A. Hexokinase II detachment from mitochondria triggers apoptosis through the permeability transition pore independent of voltage-dependent anion channels. PLoS ONE. 2008; 3(3):e1852.

35. Sharma LK, Lu J and Bai Y. Mitochondrial respiratory complex I: structure, function and implication in human diseases. Curr Med Chem. 2009; 16(10):1266-1277.

36. Rasola A, Sciacovelli M, Chiara F, Pantic B, Brusilow WS and Bernardi P. Activation of mitochondrial ERK protects cancer cells from death through inhibition of the permeability transition. Proc Natl Acad Sci U S A. 2010; 107(2):726-731.

37. Chiara F, Gambalunga A, Sciacovelli M, Nicolli A, Ronconi L, Fregona D, Bernardi P, Rasola A and Trevisan A. Chemotherapeutic induction of mitochondrial oxidative stress activates GSK- $3 \alpha / \beta$ and Bax, leading to permeability transition pore opening and tumor cell death. Cell Death and Disease. 2012; 3:e444.

38. Vidalino L, Doria A, Quarta SM, Crescenzi M, Ruvoletto M, Frezzato F, Trentin L, Turato C, Parolin MC, Ghirardello A, Iaccarino L, Cavalletto L, Chemello L, et al. SERPINB3 expression on B-cell surface in autoimmune diseases and hepatitis $\mathrm{C}$ virus-related chronic liver infection. Exp Biol Med (Maywood). 2012; 237(7):793-802.

39. Lunardi F, Villano G, Perissinotto E, Agostini C, Rea F, Gnoato M, Bradaschia A, Valente M, Pontisso P and Calabrese F. Overexpression of SERPIN B3 promotes epithelial proliferation and lung fibrosis in mice. Lab Invest. 2011; 91(6):945-954.

40. Turato C, Calabrese F, Biasiolo A, Quarta S, Ruvoletto M, Tono N, Paccagnella D, Fassina G, Merkel C, Harrison TJ, Gatta A and Pontisso P. SERPINB3 modulates TGFbeta expression in chronic liver disease. Lab Invest. 2010; 90(7):1016-1023.

41. Turato C, Buendia MA, Fabre M, Redon MJ, Branchereau S, Quarta S, Ruvoletto M, Perilongo G, Grotzer MA, Gatta A and Pontisso P. Over-expression of SERPINB3 in hepatoblastoma: a possible insight into the genesis of this tumour? Eur J Cancer. 2012; 48(8):1219-1226.

42. Quarta S, Vidalino L, Turato C, Ruvoletto M, Calabrese F, Valente M, Cannito S, Fassina G, Parola M, Gatta A and Pontisso P. SERPINB3 induces epithelial-mesenchymal transition. J Pathol. 2010; 221(3):343-356.

43. Sueoka K, Nawata S, Nakagawa T, Murakami A, Takeda O, Suminami Y, Kato H and Sugino N. Tumor-associated serpin, squamous cell carcinoma antigen stimulates matrix metalloproteinase-9 production in cervical squamous cell carcinoma cell lines. Int J Oncol. 2005; 27(5):1345-1353.

44. Jezek P and Hlavata L. Mitochondria in homeostasis of 
reactive oxygen species in cell, tissues, and organism. Int $\mathrm{J}$ Biochem Cell Biol. 2005; 37(12):2478-2503.

45. Grek CL and Tew KD. Redox metabolism and malignancy. Curr Opin Pharmacol. 2010; 10(4):362-368.

46. Pontisso P, Quarta S, Caberlotto C, Beneduce L, Marino M, Bernardinello E, Tono N, Fassina G, Cavalletto L, Gatta A and Chemello L. Progressive increase of SCCA-IgM immune complexes in cirrhotic patients is associated with development of hepatocellular carcinoma. Int $\mathrm{J}$ Cancer. 2006; 119(4):735-740.

47. Baracca A, Chiaradonna F, Sgarbi G, Solaini G, Alberghina L and Lenaz G. Mitochondrial Complex I decrease is responsible for bioenergetic dysfunction in K-ras transformed cells. Biochim Biophys Acta. 2010; 1797(2):314-323.

48. Sciacovelli M, Guzzo G, Morello V, Frezza C, Zheng L, Nannini N, Calabrese F, Laudiero G, Esposito F, Landriscina M, Defilippi P, Bernardi P and Rasola A. The mitochondrial chaperone TRAP1 promotes neoplastic growth by inhibiting succinate dehydrogenase. Cell Metab. 2013; 17(6):988-999.

49. Fassetta M, D'Alessandro L, Coltella N, Di Renzo MF and Rasola A. Hepatocyte growth factor installs a survival platform for colorectal cancer cell invasive growth and overcomes p38 MAPK-mediated apoptosis. Cell Signal. 2006; 18(11):1967-1976.

50. Gramaglia D, Gentile A, Battaglia M, Ranzato L, Petronilli V, Fassetta M, Bernardi P and Rasola A. Apoptosis to necrosis switching downstream of apoptosome formation requires inhibition of both glycolysis and oxidative phosphorylation in a BCL-X(L)- and PKB/AKTindependent fashion. Cell Death Differ. 2004; 11(3):342353. 